\title{
Chiari I malformation with and without basilar invagination: a comparative study
}

\author{
Jörg Klekamp, MD \\ Department of Neurosurgery, Christliches Krankenhaus, Quakenbrück, Germany
}

OBJECT Chiari I malformation is the most common craniocervical malformation. Its combination with basilar invagination in a significant proportion of patients is well established. This study presents surgical results for patients with Chiari I malformation with and without additional basilar invagination.

METHODS Three hundred twenty-three patients underwent 350 operations between 1985 and 2013 (mean age $43 \pm$ 16 years, mean history of symptoms $64 \pm 94$ months). The clinical courses were documented with a score system for individual neurological symptoms for short-term results after 3 and 12 months. Long-term outcomes were analyzed with Kaplan-Meier statistics. The mean follow-up was $53 \pm 58$ months (the means are expressed \pm SD).

RESULTS Patients with $(n=46)$ or without $(n=277)$ basilar invagination in addition to Chiari I malformation were identified. Patients with invagination were separated into groups: those with $(n=31)$ and without $(n=15)$ ventral compression by the odontoid in the foramen magnum. Of the 350 operations, 313 dealt with the craniospinal pathology, 28 surgeries were undertaken for degenerative diseases of the cervical spine, 3 were performed for hydrocephalus, and 6 syrinx catheters were removed for cord tethering. All craniospinal operations included a foramen magnum decompression with arachnoid dissection, opening of the fourth ventricle, and a duraplasty. In patients without invagination, craniospinal instability was detected in 4 individuals, who required additional craniospinal fusion. In patients with invagination but without ventral compression, no stabilization was added to the decompression. In all patients with ventral compression, craniospinal stabilization was performed with the foramen magnum decompression, except for 4 patients with mild ventral compression early in the series who underwent posterior decompression only. Among those with ventral compression, 9 patients with caudal cranial nerve dysfunctions underwent a combination of transoral decompression with posterior decompression and fusion.

Within the 1st postoperative year, neurological scores improved for all symptoms in each patient group, with the most profound improvement for occipital pain. In the long term, late postoperative deteriorations were related to reobstruction of CSF flow in patients without invagination (18.3\% in 10 years), whereas deteriorations in patients with invagination (24.9\% in 10 years) were exclusively related either to instabilities becoming manifest after a foramen magnum decompression or to hardware failures. Results for ventral and posterior fusions for degenerative disc diseases in these patients indicated a trend for better long-term results with posterior operations.

CONCLUSIONS The great majority of patients with Chiari I malformations with or without basilar invagination report postoperative improvements with this management algorithm. There were no significant differences in short-term or long-term outcomes between these groups. Chiari I malformations without invagination and those with invaginations but without ventral compression can be managed by foramen magnum decompression alone. The majority of patients with ventral compression can be treated by posterior decompression, realignment, and stabilization, reserving anterior decompressions for patients with profound, symptomatic brainstem compression.

http://thejns.org/doi/abs/10.3171/2015.1.FOCUS14783

KEY WORDS basilar invagination; Chiari I malformation; syringomyelia; craniospinal instability; Klippel-Feil syndrome

SUBMITTED November 23, 2014. ACCEPTED January 29, 2015.

INCLUDE WHEN CITING DOI: 10.3171/2015.1.FOCUS14783.

DISCLOSURE The author reports no conflict of interest concerning the materials or methods used in this study or the findings specified in this paper. 
$\mathrm{T}$ HE management of Chiari I malformations and basilar invaginations has been quite controversial in recent years. Issues such as whether the dura mater should be opened, if duraplasties are required, or whether the arachnoid should be opened have been discussed for patients with Chiari I malformations, and the necessity for transoral decompressions in basilar invagination has been questioned, emphasizing that realignment and C1-2 fusion is sufficient. Although most patients with basilar invagination will also demonstrate a Chiari I malformation, almost all studies on basilar invagination concentrate on the bony realignment and fusion, but do not address the management of the associated Chiari I malformation.

In this paper the results of surgical treatment for patients with Chiari I malformations with and without basilar invagination presenting between 1985 and 2013 are documented and compared.

\section{Methods}

Between 1985 and 2013 surgery was performed in 323 patients with a Chiari I malformation with or without basilar invagination in the neurosurgical clinics of Nordstadt Krankenhaus in Hannover (1985-2003) and at the Christliches Krankenhaus in Quakenbrück (2004-2013), Germany. In 1991 a spinal cord database was started, and since then information has been entered for all patients with craniocervical and spinal cord pathologies. All patients were followed up and data incorporated into the database continuously up to the present day. Nineteen patients underwent operation between 1985 and 1990 and were incorporated retrospectively. For this publication, all data up to 2013 were analyzed. In this cohort, 277 patients with Chiari I malformation without basilar invagination underwent 300 operations, and 46 patients with basilar invagination in addition to the Chiari I malformation underwent 50 operations.

Apart from general patient data and associated features of this pathology, the neurological examinations before surgery, before discharge from the hospital, after 3 months postoperatively, and yearly thereafter were documented for individual symptoms according to a scoring system devised by Klekamp and Samii, ${ }^{31}$ adding a score developed subsequently for swallowing function ${ }^{29}$ (Table 1). This scoring system was used for descriptive purposes only, to illustrate postoperative courses of individual symptoms.

All patients underwent MRI of the head and cervical spine. Basilar invagination was defined as the odontoid crossing the Chamberlain line between the hard palate and posterior rim of the foramen magnum for more than 5 $\mathrm{mm} .{ }^{10,54}$ Preoperative CT scans and radiographs of the cervical spine in ante- and retroflexion were obtained in each patient with basilar invagination, and combined with CT angiography in patients with narrow margins for screw placement at C-1 or C-2. Whenever a spinal stabilization was planned, a lateral radiograph in neutral position was obtained for exact intraoperative positioning.

Surgery was recommended for symptomatic patients only. All posterior operations were performed with the patient placed prone and involved a decompression of the foramen magnum with opening of dura and arachnoid, as well as a duraplasty to establish and maintain a physiological CSF flow ${ }^{29,30,32}$ (Fig. 1). Patients undergoing a spinal stabilization were placed in the neutral position with the cervical spine extended under fluoroscopic control according to the preoperative radiograph. The bony decompression consisted of a craniectomy of 3- to 4-cm diameter, which included the foramen magnum and a laminectomy of C-1 (Fig. 1). Care was taken to preserve the spinous process and arch of $\mathrm{C}-2$ to allow secure placement of a bone graft between occiput and $\mathrm{C}-2$ in patients requiring additional fusions (Fig. 2). With exposure of the dura, the atlantooccipital membrane was coagulated and dissected off the dura, which was then incised in a $Y$ shape under the microscope. The arachnoid was incised to spread the tonsils apart for inspection of the foramen of Magendie. In most instances the cerebellar tonsils were coagulated at their tips and medially for this purpose.

If the foramen was found to be patent and no arachnoid adhesions were detectable elsewhere, no further dissections were performed. Whenever the foramen was obstructed, it was opened by sharp dissection. No dissec-

TABLE 1. Neurological scoring system*

\begin{tabular}{|c|c|c|c|c|c|c|}
\hline Score & Pain & $\begin{array}{l}\text { Sensory Dist, } \\
\text { Dysesthesias }\end{array}$ & Motor Weakness & Gait Ataxia & $\begin{array}{l}\text { Sphincter } \\
\text { Function }\end{array}$ & Swallowing Function \\
\hline 5 & None & Normal & Full power & Normal & Normal & Normal \\
\hline 4 & $\begin{array}{l}\text { Slight, no medica- } \\
\text { tion }\end{array}$ & $\begin{array}{l}\text { Present, not signifi- } \\
\text { cant }\end{array}$ & $\begin{array}{l}\text { Movement against } \\
\text { resistance }\end{array}$ & $\begin{array}{l}\text { Unsteady, no } \\
\text { aid }\end{array}$ & $\begin{array}{l}\text { Slight dist, no } \\
\text { catheter }\end{array}$ & Discomfort \\
\hline 3 & $\begin{array}{l}\text { Good control with } \\
\text { medication }\end{array}$ & $\begin{array}{l}\text { Significant, function } \\
\text { not restricted }\end{array}$ & $\begin{array}{l}\text { Movement against } \\
\text { gravity }\end{array}$ & Mobile with aid & $\begin{array}{l}\text { Residual, no cath- } \\
\text { eter }\end{array}$ & $\begin{array}{l}\text { Nerve deficit com- } \\
\text { pensated }\end{array}$ \\
\hline 2 & $\begin{array}{l}\text { Insufficient control } \\
\text { with medication }\end{array}$ & $\begin{array}{l}\text { Some restriction of } \\
\text { function }\end{array}$ & $\begin{array}{l}\text { Movement without } \\
\text { gravity }\end{array}$ & $\begin{array}{l}\text { Few steps with } \\
\text { aid }\end{array}$ & Rarely incontinent & $\begin{array}{l}\text { Aspiration, coughing } \\
\text { preserved }\end{array}$ \\
\hline 1 & $\begin{array}{l}\text { Severe despite } \\
\text { medication }\end{array}$ & $\begin{array}{l}\text { Severe restriction } \\
\text { of function }\end{array}$ & $\begin{array}{l}\text { Contraction with- } \\
\text { out movement }\end{array}$ & $\begin{array}{l}\text { Standing with } \\
\quad \text { aid }\end{array}$ & Often catheter & $\begin{array}{l}\text { Aspiration, coughing } \\
\text { insufficient }\end{array}$ \\
\hline 0 & Incapacitating & $\begin{array}{l}\text { Incapacitated func- } \\
\text { tion }\end{array}$ & Plegia & Plegia & $\begin{array}{l}\text { Permanent cathe- } \\
\text { ter }\end{array}$ & No function \\
\hline
\end{tabular}



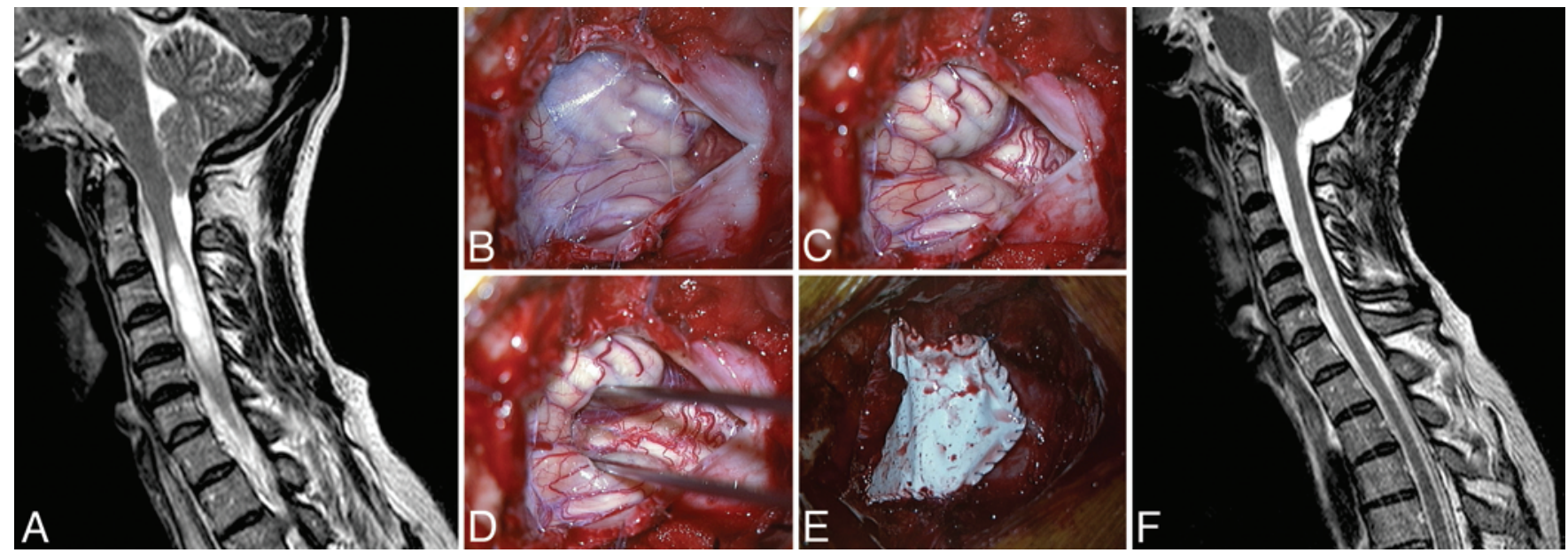

FIG. 1. A: Sagittal MRI study obtained in a 52-year-old woman with a 3-year history of occipital pain and gait ataxia shows a Chiari I malformation with syringomyelia. B-E: Intraoperative photographs. After opening of the dura mater the arachnoid appears normal (B). After bipolar coagulation of the tonsils (C), the foramen of Magendie is inspected and appears partially obstructed (D). The dura is closed with a duraplasty (E). F: The postoperative MRI obtained after 3 months demonstrates a free CSF passage at the foramen magnum and complete resolution of the syrinx. Occipital pain and gait ataxia improved.

tion was performed laterally to avoid injury to perforating vessels of the brainstem or spinal cord. A duraplasty was inserted with a running suture. A variety of materials were used for this purpose: Goretex (W.L. Gore \& Associates GmbH), Neuro-Patch (B. Braun Melsungen AG), fascia lata, or galea (Fig. 1). For patients requiring fusion, lateral mass screws have been used for the subaxial cervical spine since 2004. For C-2, pedicle screws or laminar screws were used. Prior to 2004, posterior rods were fixed to cervical laminae by soft wire. Whereas occipital rods applied laterally to the occiput were used up to 2009 , occipital plates that can be fixed to the medial and thicker parts of the occipital bone have been used since then. An iliac crest graft was placed between occiput and C-2 and fixed with small screws (Fig. 2). Additionally, bone material was placed into the $\mathrm{C} 1-2$ joints. Finally the wound was closed, paying particular attention to tight suturing of the muscular layer, which had to cover all implants completely. ${ }^{29,30,32}$

For anterior decompressions (i.e., transoral resections of the dens axis), the patients were placed supine for the operation, which was always followed by a posterior decompression and fusion a few days later. No splitting of the soft or hard palate was performed in these patients. The incision was centered at the level of the anterior arch of $\mathrm{C}-1$. The anterior part of the atlas was removed, and then the odontoid was detached from the body of C-2 at its base, according to intraoperative fluoroscopic guidance, and then removed in toto after resection of the ligaments at the odontoid tip. The wound was closed in a single layer. A gastric tube was left in place and a Philadelphia collar applied until the posterior decompression and fusion had been performed a few days later (Fig. 3).

Postoperatively, all patients were supervised on the intensive care unit for at least 24 hours before being transferred back to the regular ward. Postoperatively, all patients underwent an MRI study before discharge and a CT control study and lateral radiograph if a fusion had been performed. A further MRI study was obtained after 3-6 months. Further scans were obtained in patients with unsatisfactory clinical outcomes or in those with no resolution of an associated syrinx. For patients with posterior
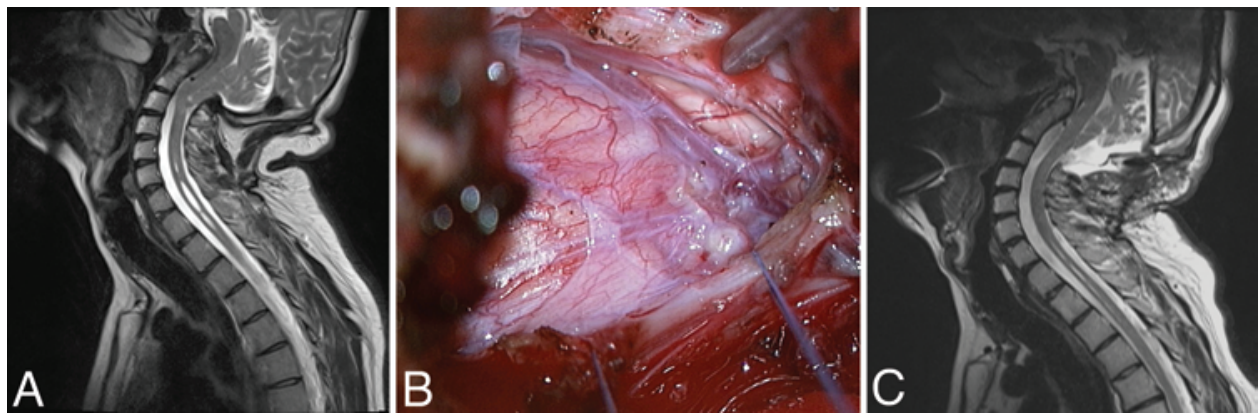

FIG. 2. A: Sagittal MRI scan of a 26 -year-old man with a 4-year history of occipital pain and gait ataxia demonstrates a Chiari I malformation with syringomyelia and a basilar invagination with ventral compression of the medulla. B: Intraoperative photograph. After dura and arachnoid opening, adhesions encasing both posterior inferior cerebellar arteries and obstructing the foramen of Magendie become apparent. C: Postoperative sagittal MRI obtained after 3 months shows the realignment achieved by extension and fixation of $\mathrm{Oc}-\mathrm{C} 3$ and a decrease of the syrinx. 

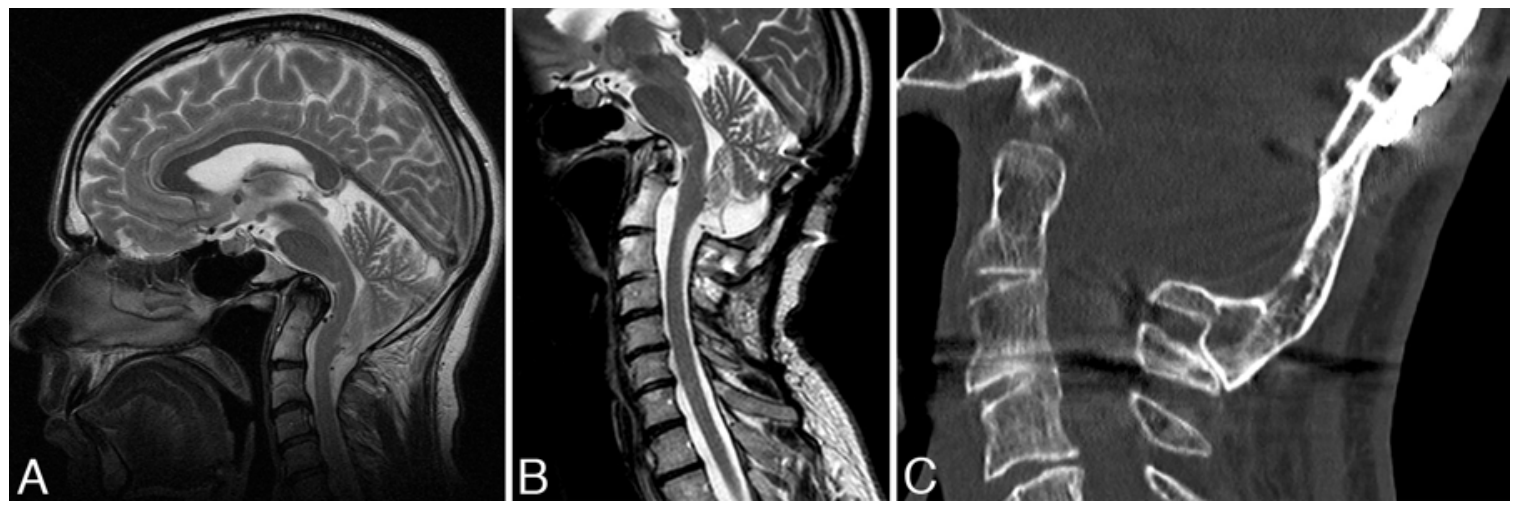

FIG. 3. A: Sagittal MRI scan of a 43-year-old man with a 3-year history of neck pain, gait ataxia, and profound swallowing dysfunctions due to ventral compression by the odontoid and posterior compression by the Chiari malformation. The patient underwent a transoral and a posterior decompression with $\mathrm{Oc}-\mathrm{C} 4$ fusion. B: Postoperative sagittal MR image shows the decompression of the upper cervical cord and medulla. C: Sagittal CT reconstruction reveals the bony fusion Oc-C4. Gait ataxia, swallowing problems, and neck pain improved.

fusions, CT scans were ordered 1 year after the operation to rule out hardware problems.

For statistical tests of significance, Student t-tests and Fisher tests were used. Long-term follow-up was analyzed with Kaplan-Meier ${ }^{26}$ statistics to determine percentages of patients with and without postoperative clinical recurrences. A clinical recurrence was defined as a new neurological deficit or a worsening of a preoperative deficit after surgery. For all statistical analyses the software package PC-Stastik version 4.0 was used (Hoffmann-Software).

\section{Results}

\section{Clinical Presentations and Anatomical Features}

Three hundred twenty-three patients with a Chiari I malformation underwent 350 operations between 1985 and 2013 , with a follow-up of $53 \pm 58$ months (mean \pm SD). Preoperative symptoms are presented in Table 2, and patient data in Table 3. There were 16 children and 307 adults in this series.

Patients with Chiari I malformation and basilar invagination were significantly less affected by neuropathic pain and sensory deficits compared with patients with a Chiari I malformation alone, but these patients were more severely compromised by gait ataxia and swallowing dysfunctions. Furthermore, they were significantly younger and demonstrated syringomyelia less often and of smaller size if present.

Looking at additional bony anomalies, patients with invagination were more commonly affected by assimilations of the atlas to the occiput or Klippel-Feil syndrome of the cervical spine. Functional radiographs disclosed craniospinal instability significantly more often in patients with invagination than in those without $(65.2 \%$ and $2.7 \%$, respectively).

Despite the younger age for patients with invagination in addition to Chiari I malformation, the average preoperative history was almost identical in both groups, and extended for approximately 5.5 years on average.

\section{Craniocervical Operations}

Surgery was offered to all symptomatic patients; 313 operations dealt with the craniospinal pathology-consisting of a foramen magnum decompression, arachnoid dissection, and a duraplasty with or without stabilization. Of these, 56 operations were secondary interventions (47 in patients without invagination, 9 in those with invagination). Intraoperatively, severe arachnoid scarring was evident in $15 \%$ of all decompressions, without a significant difference between those with or without additional invagination (16\% and 13\%, respectively). The foramen of Magendie was found to be closed by a membrane in $36 \%$ of all foramen magnum decompressions, and it was opened in these patients (Fig. 1). There was again no difference in this respect between patients with or without additional invagination (34\% and 36\%, respectively).

Patients without invagination but with evidence of craniocervical instability underwent the decompression with additional craniospinal fixation. Patients with invagination were divided into those with $(n=31)$ or without $(n=$ 15 ) ventral compression by the odontoid in the foramen magnum. Patients with ventral compression were significantly more likely to present with swallowing problems

TABLE 2. Preoperative neurological symptoms

\begin{tabular}{lccccccc}
\hline \multicolumn{1}{c}{ Group } & Occipital Pain & Neuropathic Pain & Hypesthesia & Gait & Motor Power & $\begin{array}{c}\text { Sphincter } \\
\text { Function }\end{array}$ & $\begin{array}{c}\text { Swallowing } \\
\text { Function }\end{array}$ \\
\hline Chiari I malformation & $79 \%$ & $48 \%^{*}$ & $70 \%^{*}$ & $65 \%^{*}$ & $41 \%$ & $15 \%$ & $16 \%^{*}$ \\
\hline Chiari I + invag & $86 \%$ & $34 \%^{*}$ & $56 \%^{*}$ & $86 \%^{*}$ & $34 \%$ & $10 \%$ & $32 \%{ }^{*}$ \\
\hline All & $80 \%$ & $46 \%$ & $68 \%$ & $68 \%$ & $40 \%$ & $14 \%$ & $18 \%$ \\
\hline Invag = invagination. & & & & & & \\
* Significant difference $(\mathrm{p}<0.05)$ between groups.
\end{tabular}


TABLE 3. Clinical data and surgical management

\begin{tabular}{|c|c|c|c|}
\hline Variable & Chiari I & $\begin{array}{c}\text { Chiari I + } \\
\text { Invag }\end{array}$ & All \\
\hline \multicolumn{4}{|l|}{ Clinical data } \\
\hline No. of patients & 277 & 46 & 323 \\
\hline Age (mean \pm SD) & $44 \pm 15 \mathrm{yrs}^{*}$ & $38 \pm 18 \mathrm{yrs}^{*}$ & $43 \pm 16$ yrs \\
\hline $\begin{array}{l}\text { Sx duration (mean } \\
\quad \pm \text { SD) }\end{array}$ & $64 \pm 96 \mathrm{mos}$ & $66 \pm 88 \mathrm{mos}$ & $64 \pm 94 \mathrm{mos}$ \\
\hline Syringomyelia & $223^{*}$ & $31^{*}$ & 254 \\
\hline Craniospinal instability & $4^{*}$ & $30^{*}$ & 34 \\
\hline Atlas assimilation & $2^{*}$ & $26^{*}$ & 28 \\
\hline Klippel-Feil syndrome & $7^{*}$ & $17^{*}$ & 24 \\
\hline \multicolumn{4}{|l|}{ Management } \\
\hline Pst decompression† & 264 & 19 & 283 \\
\hline $\begin{array}{l}\text { Pst decompression + } \\
\text { pst fusion }\end{array}$ & 4 & 17 & 21 \\
\hline $\begin{array}{l}\text { Combined dec + pst } \\
\text { fusiont }\end{array}$ & 0 & 9 & 9 \\
\hline $\begin{array}{l}\text { Syrinx catheter re- } \\
\text { moval }\end{array}$ & 6 & 0 & 6 \\
\hline VP shunt & 3 & 0 & 3 \\
\hline $\begin{array}{l}\text { Ventral fusion cervical } \\
\text { spine }\end{array}$ & 16 & 4 & 20 \\
\hline $\begin{array}{l}\text { Pst fusion cervical } \\
\text { spine }\end{array}$ & 7 & 1 & 8 \\
\hline Total & 300 & 50 & 350 \\
\hline
\end{tabular}

Combined dec = transoral and posterior decompression; $p s t=$ posterior $; \mathrm{Sx}=$ symptom; $\mathrm{VP}=$ ventriculoperitoneal.

* Significant difference $(p<0.05)$ between groups.

$\dagger$ Two patients with ventral compression underwent subsequent stabilizations after a posterior decompression. Two patients required repeat fixations after combined decompressions and fusions due to hardware failures.

than were those without ventral compression $(39 \%$ and $12 \%$, respectively).

In the group with basilar invagination, all patients without ventral compression underwent a foramen magnum decompression without additional stabilization (Fig. 4). Another 4 patients with mild anterior compression were also treated without fusion. Among these 4 patients treated without fusion, 3 developed instabilities subsequently. Two of the 3 had segmentation abnormalities, with assimilation of the atlas in 1 and Klippel-Feil syndrome in both of them. The third patient had presented without segmentation abnormalities but with a profound swan neck deformity. Two of these patients underwent stabilizations in a second operation. The third patient refused further surgery and died 7 years later due to respiratory failure.

In the group with basilar invagination and ventral compression, 15 operations consisted of a foramen magnum decompression with fixation (Fig. 2). All fixations included the occiput, with 1 exception; that patient underwent a C1-2 fusion. In another 9 patients with ventral compression and signs of caudal cranial nerve deficits, a transoral resection of the odontoid was performed first, followed by the posterior decompression and fusion (Fig. 3). Of these 9 patients, 2 required refixations at the occiput 2 and 3 years later due to hardware failures early in the series.
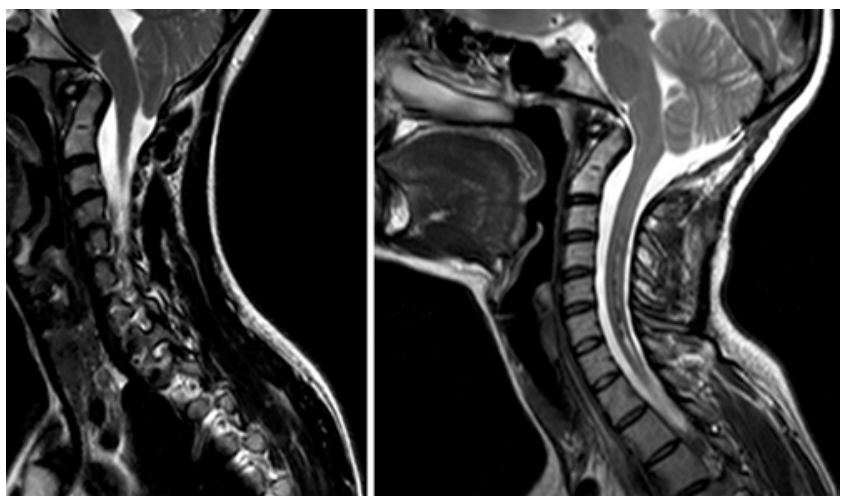

FIG. 4. Left: Sagittal MRI scan of a 31-year-old woman with sensory deficits and neuropathic pain in her left arm for the past 10 years demonstrates a Chiari I malformation, a basilar invagination without ventral compression, and a scoliosis of her entire spine. A profound syrinx extended from C-3 to T-3. The patient underwent a foramen magnum decompression without fusion. Right: Sagittal postoperative MRI shows the free CSF passage at the foramen magnum and a decrease of the syrinx. Her neuropathic pain improved corresponding to a significant reduction of her analgesic medication.

\section{Spine Operations}

In the group without invagination, 6 operations were performed to remove syrinx shunt catheters implanted at other institutions, because these had caused symptoms related to cord tethering. Three patients were primarily treated for their hydrocephalus only.

Another group of operations addressed degenerative diseases of the cervical spine after sufficient treatment of the craniospinal pathologies (Fig. 5). These surgeries made up $8 \%$ of all operations consisting of posterior or anterior decompressions and fusions (Table 3). Ventral fusions were chosen for patients with radicular symptoms, whereas posterior decompressions and fusions were used for patients presenting with a progressive myelopathy.

\section{Postoperative Outcome for Craniocervical Operations}

After foramen magnum decompressions with or without fusions, complications within 30 days were observed in $19.2 \%$, and were significantly more common in patients with than in those without basilar invagination in addition to Chiari I malformation (35.6\% and $16.4 \%$, respectively; $\mathrm{p}$ $=0.0006$ ) (Table 4). Whereas complications in the Chiari group without invagination were predominantly related to the foramen magnum, complications unrelated to the foramen magnum such as pneumonias were more common in the group with additional invagination.

Syringomyelia declined after $74 \%$ of all operations and remained stable in $23 \%$. The rate for postoperative increases was very low, at $3 \%$. Due to the smaller syrinx sizes in patients with invagination, the rate of syrinx cavities remaining unchanged was higher in this group, without reaching statistical significance ( $41 \%$ and $21 \%$, respectively).

Looking at short-term results for the 1st postoperative year after decompressions (Table 5), both groups experienced profound improvements for occipital pain with minor improvements for the remaining symptoms. At this 

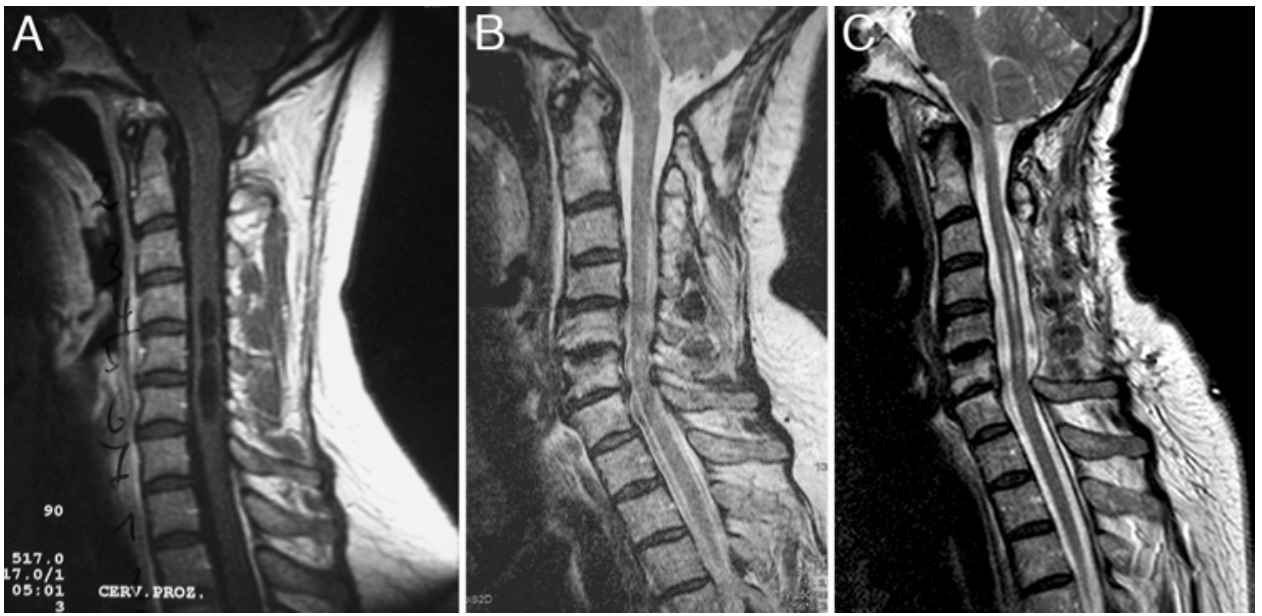

FIG. 5. A: Sagittal MRI scan of a 38-year-old woman with a Chiari I malformation and syringomyelia at C4-6. The patient underwent a foramen magnum decompression leading to resolution of the syrinx. Six years later a ventral fusion C5-6 was performed for treatment of radicular symptoms. Another 10 years later the patient presented with signs of a cervical myelopathy. B: The sagittal MRI at this time shows the free CSF passage at the foramen magnum, no reappearance of the syrinx, and multiple osteochondroses. C: After laminectomies of C3-6 and fusion of C3-7, the sagittal MRI shows the decompression of the cervical spinal cord. Neck pain and gait ataxia improved.

time point, only $4 \%$ considered their neurological status to be worsened by the operation, with the rate for postoperative improvements being higher for those with additional invagination than in those without $(81.6 \%$ and $76.4 \%$, respectively).

The analysis of long-term results revealed no significant difference between patients with or without basilar invagination in addition to Chiari I malformation. Rates for clinical recurrences within 5 and 10 years were not significantly different according to Kaplan-Meier analysis, although a smaller proportion of patients without invagination tended to develop new neurological deficits in the long term (Chiari I: $13.2 \%$ and 18.3\%; Chiari I with invagination: $24.9 \%$ and $24.9 \%$ after 5 and 10 years, respectively; log-rank test: not significant) (Fig. 6). Clinical recurrences

TABLE 4. Complications after craniospinal decompressions with and without fusions

\begin{tabular}{lccc}
\hline \multicolumn{1}{c}{ Complication } & Chiari I & Chiari I + Invag & All \\
\hline CSF fistula & 11 & 1 & 12 \\
\hline Wound infection & 8 & 2 & 10 \\
\hline Hydrocephalus & 7 & 3 & 10 \\
\hline Hemorrhage & 3 & 0 & 3 \\
\hline Swallowing dysf & 1 & 1 & 2 \\
\hline Cerebellar infarction & 1 & 0 & 1 \\
\hline Instability & 0 & 1 & 1 \\
\hline UTI & 9 & 2 & 11 \\
\hline Pneumonia & 3 & 5 & 8 \\
\hline Thrombophlebitis & 1 & 0 & 1 \\
\hline Angioneurotic edema & 0 & 1 & 1 \\
\hline Total & $44(16.4 \%)$ & $16(35.6 \%)$ & $60(19.2 \%)$ \\
\hline
\end{tabular}

Dysf = dysfunction; $\mathrm{UTI}=$ urinary tract infection. in patients with invagination were exclusively related either to instabilities becoming manifest after a foramen magnum decompression (3 patients) or to a hardware failure (2 patients). Postoperative neurological deteriorations for patients without invagination were more evenly spread during follow-up and were predominantly related to reobstructions of the CSF passage at the foramen magnum.

A comparison between primary and secondary decompressions revealed significantly higher clinical recurrence rates in the group without additional invagination for secondary interventions, due to the profound arachnoid pathology in this subgroup (first surgery: $8 \%$ and 9.6\%; revision surgery: $28.3 \%$ and $37.3 \%$ after 5 and 10 years, respectively; log-rank test: $\mathrm{p}=0.0005$ ) (Fig. 7). A similar difference for patients with invagination was not detectable (first surgery: 29.4\% and 29.4\%; revision surgery: $14.3 \%$ and $14.3 \%$ after 5 and 10 years, respectively; log-rank test: not significant) (Fig. 8), presumably because instability was the major reason for revision rather than reobstruction of the CSF pathway at the foramen magnum. In absolute numbers, 15 of 230 patients without invagination and 5 of 37 patients with invagination demonstrated a postoperative clinical recurrence after a first decompression, requiring a surgical revision in 4 patients without and 3 patients with invagination.

\section{Postoperative Outcome for Spine Operations}

For patients treated for their degenerative cervical disc disease, $81.5 \%$ reported a postoperative improvement of their symptoms after surgery, whereas the remainder considered their condition unchanged or worse. Looking at individual symptoms, the postoperative results were very similar to those observed after foramen magnum decompressions. Occipital pain and gait ataxia responded best, with marginal improvements for the remainder of symptoms (Table 5).

The analysis of long-term results for patients treated 
TABLE 5. Neurological course in the 1st postoperative year*

\begin{tabular}{|c|c|c|c|c|}
\hline \multirow[b]{2}{*}{ Symptom } & \multicolumn{3}{|c|}{ Decompressions } & \multirow[b]{2}{*}{ All Cervical Fusions } \\
\hline & Chiari I & Chiari I + Invag & All Craniocervical & \\
\hline \multicolumn{5}{|l|}{ Hypesthesia } \\
\hline Preop & $3.7 \pm 0.9$ & $4.1 \pm 0.9$ & $3.7 \pm 1.0$ & $3.7 \pm 0.8$ \\
\hline Postop & $3.8 \pm 0.9$ & $4.2 \pm 0.8$ & $3.9 \pm 0.9$ & $3.8 \pm 0.8$ \\
\hline $3 \mathrm{mos}$ & $3.9 \pm 0.9$ & $4.3 \pm 0.9$ & $4.0 \pm 0.9$ & $3.9 \pm 0.8$ \\
\hline $1 \mathrm{yr}$ & $4.0 \pm 0.9$ & $4.3 \pm 0.7$ & $4.0 \pm 0.9$ & $4.0 \pm 0.8$ \\
\hline \multicolumn{5}{|c|}{ Neuropathic pain } \\
\hline Preop & $4.2 \pm 0.9$ & $4.5 \pm 0.8$ & $4.2 \pm 0.9$ & $4.4 \pm 0.9$ \\
\hline Postop & $4.3 \pm 0.8$ & $4.6 \pm 0.7$ & $4.4 \pm 0.8$ & $4.5 \pm 0.9$ \\
\hline 3 mos & $4.4 \pm 0.8$ & $4.6 \pm 0.7$ & $4.4 \pm 0.8$ & $4.5 \pm 0.9$ \\
\hline $1 \mathrm{yr}$ & $4.4 \pm 0.8$ & $4.6 \pm 0.7$ & $4.4 \pm 0.8$ & $4.5 \pm 0.9$ \\
\hline \multicolumn{5}{|l|}{ Occipital pain } \\
\hline Preop & $3.6 \pm 0.9$ & $3.4 \pm 0.8$ & $3.6 \pm 0.9$ & $3.6 \pm 0.9$ \\
\hline Postop & $4.1 \pm 0.6$ & $3.8 \pm 0.7$ & $4.1 \pm 0.7$ & $4.1 \pm 0.7$ \\
\hline $3 \mathrm{mos}$ & $4.4 \pm 0.7$ & $4.1 \pm 0.7$ & $4.3 \pm 0.7$ & $4.3 \pm 0.6$ \\
\hline $1 \mathrm{yr}$ & $4.4 \pm 0.7$ & $4.2 \pm 0.8$ & $4.4 \pm 0.7$ & $4.2 \pm 0.6$ \\
\hline \multicolumn{5}{|c|}{ Motor weakness } \\
\hline Preop & $4.3 \pm 0.9$ & $4.6 \pm 0.6$ & $4.3 \pm 0.9$ & $4.0 \pm 0.9$ \\
\hline Postop & $4.3 \pm 0.9$ & $4.6 \pm 0.6$ & $4.4 \pm 0.9$ & $4.1 \pm 0.8$ \\
\hline $3 \mathrm{mos}$ & $4.4 \pm 0.9$ & $4.6 \pm 0.6$ & $4.4 \pm 0.9$ & $4.3 \pm 0.8$ \\
\hline $1 \mathrm{yr}$ & $4.4 \pm 0.9$ & $4.7 \pm 0.6$ & $4.4 \pm 0.9$ & $4.3 \pm 0.8$ \\
\hline \multicolumn{5}{|l|}{ Gait ataxia } \\
\hline Preop & $4.0 \pm 1.0$ & $3.8 \pm 0.7$ & $4.0 \pm 0.9$ & $3.8 \pm 1.1$ \\
\hline Postop & $4.1 \pm 1.0$ & $3.9 \pm 0.7$ & $4.1 \pm 0.9$ & $3.8 \pm 1.1$ \\
\hline $3 \mathrm{mos}$ & $4.3 \pm 1.0$ & $4.1 \pm 0.5$ & $4.3 \pm 0.9$ & $4.0 \pm 1.0$ \\
\hline $1 \mathrm{yr}$ & $4.3 \pm 1.0$ & $4.2 \pm 0.6$ & $4.3 \pm 0.9$ & $4.1 \pm 0.9$ \\
\hline \multicolumn{5}{|l|}{ Bladder function } \\
\hline Preop & $4.8 \pm 0.7$ & $4.8 \pm 0.7$ & $4.8 \pm 0.7$ & $4.8 \pm 0.6$ \\
\hline Postop & $4.8 \pm 0.6$ & $4.9 \pm 0.4$ & $4.8 \pm 0.6$ & $4.8 \pm 0.6$ \\
\hline $3 \mathrm{mos}$ & $4.8 \pm 0.6$ & $4.9 \pm 0.2$ & $4.8 \pm 0.6$ & $4.8 \pm 0.5$ \\
\hline $1 \mathrm{yr}$ & $4.8 \pm 0.6$ & $4.9 \pm 0.2$ & $4.8 \pm 0.6$ & $4.8 \pm 0.5$ \\
\hline \multicolumn{5}{|l|}{ Swallowing } \\
\hline Preop & $4.8 \pm 0.6$ & $4.5 \pm 0.8$ & $4.7 \pm 0.6$ & \\
\hline Postop & $4.9 \pm 0.5$ & $4.6 \pm 0.7$ & $4.8 \pm 0.5$ & \\
\hline $3 \mathrm{mos}$ & $4.9 \pm 0.4$ & $4.7 \pm 0.5$ & $4.9 \pm 0.4$ & \\
\hline $1 \mathrm{yr}$ & $4.9 \pm 0.4$ & $4.8 \pm 0.5$ & $4.9 \pm 0.4$ & \\
\hline \multicolumn{5}{|l|}{ Overall } \\
\hline Better & $76.4 \%$ & $81.6 \%$ & $77.1 \%$ & $81.5 \%$ \\
\hline Unchanged & $19.2 \%$ & $16.3 \%$ & $18.9 \%$ & $14.8 \%$ \\
\hline Worse & $4.4 \%$ & $2.0 \%$ & $4.0 \%$ & $3.7 \%$ \\
\hline
\end{tabular}

* Unless otherwise specified, all values are expressed as the mean \pm SD.

for their degenerative cervical disc diseases revealed no postoperative clinical recurrences for those with additional invaginations. However, follow-up was limited to 26 months in this subgroup. In the group without invagination, 5 patients reported neurological deteriorations due to adjacent-level disease. In 4 of these, a ventral fusion in 1 or 2 segments had been performed (Fig. 5). Among patients treated by posterior decompression with laminectomy of C3-6 and fusion of C3-6 or C3-7, only 1 clinical recur- rence was detected. The maximum follow-up in this subgroup was 10 years.

\section{Discussion}

\section{History and Diagnosis}

Except for 16 children between 12 and 17 years of age, all other patients in this series were adults. Basilar invagination was detected in $14.2 \%$ of all patients presenting 


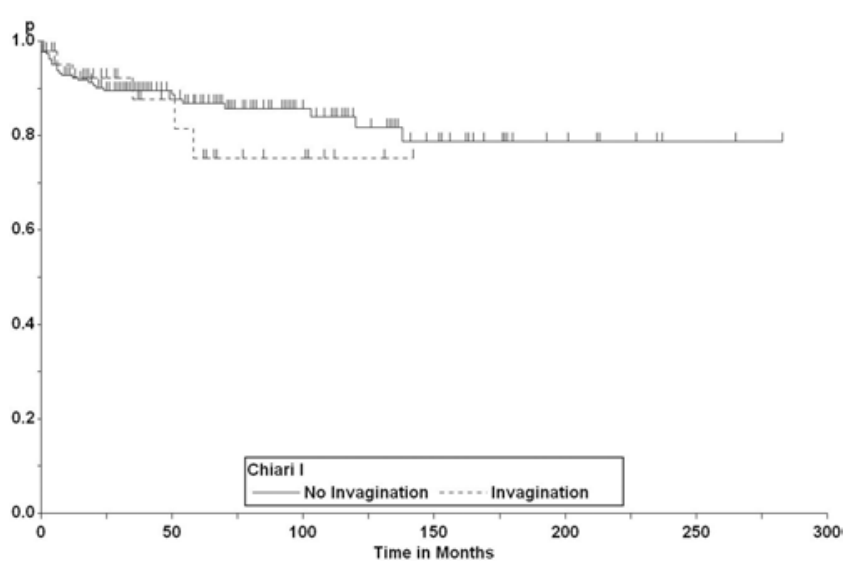

FIG. 6. Kaplan-Meier analysis for clinical recurrence rates after foramen magnum decompressions in patients with Chiari I malformation with and without basilar invagination (log-rank test: no significant difference).

with a Chiari I malformation. Among their series of 364 adult patients with Chiari I malformation, Milhorat et al..$^{40}$ reported a comparable rate of $12 \%$ for patients with basal invagination.

The clinical history extended over 5.5 years irrespective of the presence or absence of invagination. Symptoms started most commonly with occipital pain or gait ataxia, and these remained the major complaints by the time of presentation. There were some differences between patients with or without invagination, however. Patients with invagination tended to be more affected by caudal cranial nerve deficits and gait disturbances due to the additional ventral compression, whereas patients without invagination were more likely to suffer also from neuropathic pain or sensory disturbances, which was most likely related to higher rates of syringomyelia in patients without invagination. Moreover, syrinx cavities tended to be smaller in the invagination group, which suggests that a high percentage of them were asymptomatic. Nevertheless, the combination of anterior as well as posterior compression with $\mathrm{C} 1-2$ instability may lead to very dangerous and rapid clinical deteriorations. ${ }^{3}$ If the diagnosis has been made and clinical signs of a high cervical myelopathy are present, early surgery should be recommended.

The radiological diagnosis of a Chiari I malformation is almost always made by MRI. In the presence of invagination, however, additional radiological examinations are mandatory to establish all associated features. The diagnostic workup has to include a detailed analysis of the bony and vascular anatomy as well as functional studies apart from an MRI image. Preoperative CT scans with reconstructions in sagittal and coronal planes are extremely helpful for surgical planning to evaluate the bony anatomy of the craniocervical junction (Table 3).$^{20}$ In combination with a CT angiography study, the exact courses of the vertebral arteries can be demonstrated to avoid vascular injuries during surgery. The CT studies in ante- and retroflexion allow a good evaluation of functional aspects (such as instabilities of $\mathrm{C1}-2$, in particular). Functional radiographs may serve the same purpose. However, the often short necks of these patients may make a good visualization of the C1-2 segment difficult. Segmentation anomalies such

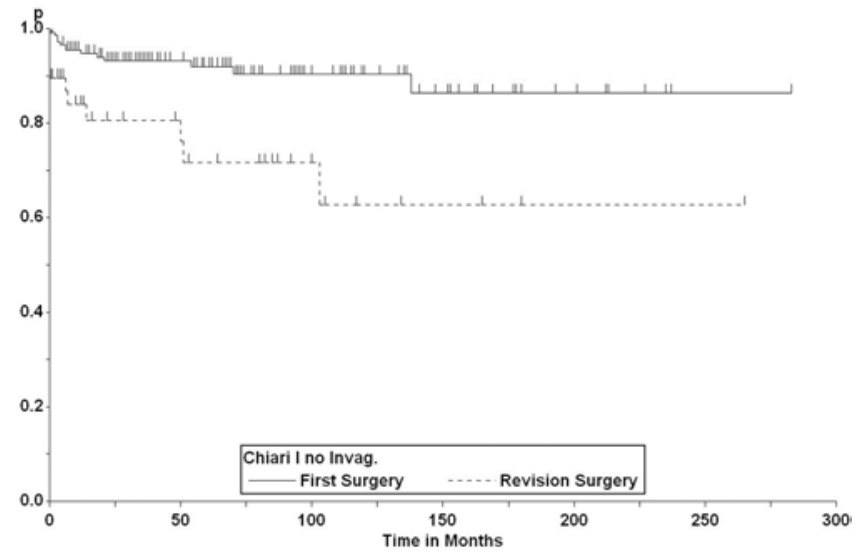

FIG. 7. Kaplan-Meier analysis for clinical recurrence rates after first and secondary foramen magnum decompressions in patients with Chiari I malformation (log-rank test: $p=0.0005)$. Invag. = invagination.

as fusion of the atlas to the occiput or Klippel-Feil syndrome of the subaxial spine were much more common in the invagination group and should always be considered as features predisposing to craniocervical instability in patients with a Chiari I malformation.

\section{Management of the Craniocervical Pathology}

Symptomatic patients with Chiari I malformation require a decompression of the foramen magnum. But how should this decompression be designed? If a basilar invagination is present as well, do these patients require a ventral, transoral decompression? Is a sagittal realignment and posterior fusion sufficient for these patients, or should a foramen magnum decompression be performed as well?

The ongoing debate on the optimal foramen magnum decompression cannot be solved with this paper because all patients were treated in the same pattern: they underwent a suboccipital craniectomy enlarging the foramen magnum, a laminectomy C-1, dura and arachnoid opening, opening of the fourth ventricle if obstructed, and a duraplasty (Fig. 1). A detailed analysis of results incorporating data from the Department of Neurosurgery at the University of California Los Angeles had established the superiority of this technique compared with interventions that left the arachnoid intact. ${ }^{29,32}$

For patients with basilar invagination, some publications suggest that a ventral decompression alone, ${ }^{13,37}$ cervical traction, ${ }^{24}$ or posterior sagittal realignment and fusion with or without a bony decompression ${ }^{17,22,23}$ may be sufficient. In this series, a foramen magnum decompression was always incorporated into the procedure rather than limiting the operation to posterior alignment and fusion, because the realignment does release the ventral compression by the odontoid but not necessarily the posterior compression by the cerebellar tonsils and the CSF obstruction associated with it (Fig. 2).

The treatment algorithm (Fig. 9) presented here stratifies patients according to the presence or absence of a basilar invagination and distinguishes further between patients with (Fig. 2) or without ventral compression by the odontoid peg (Fig. 4). Patients without ventral compression do 


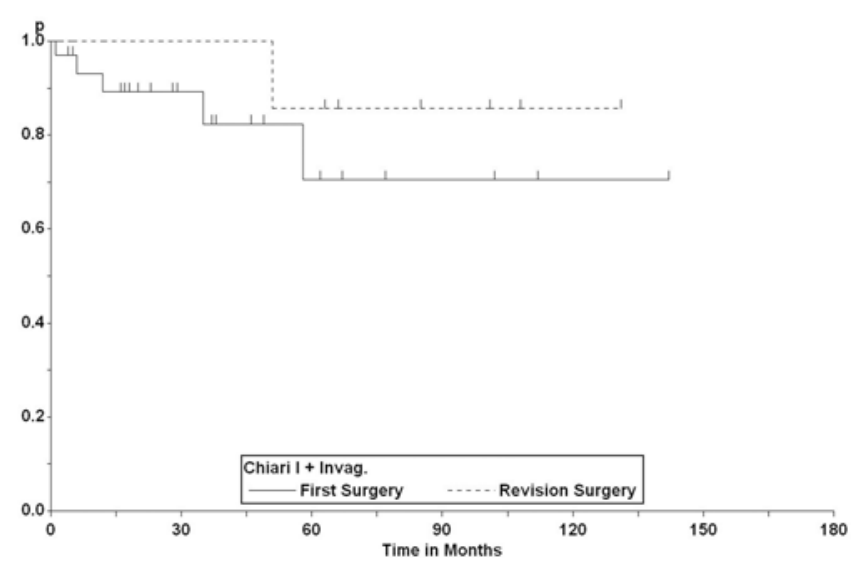

FIG. 8. Kaplan-Meier analysis for clinical recurrence rates after first and secondary foramen magnum decompressions in patients with Chiari I malformation and basilar invagination (log-rank test: no significant difference).

not require a reduction of a ventral component and can be treated by a foramen magnum decompression aloneunless instability is likely to develop due to segmentation anomalies demonstrated on preoperative functional images or detected during surgery, in which case fusion should be added..$^{18}$

Preoperative functional radiographs or CT scans may not pick up instabilities, however, because patients may restrict their range of motion according to their biomechanical limitations. Measurements of several angles between different skull base structures and the upper cervical spine have been proposed and used to aid in the determination whether craniocervical instability is present or likely to be so. ${ }^{7,54}$ Such measurements were not used in this series, and whether they would have been useful in deciding if fu- sion should be performed in patients without ventral compression cannot be evaluated in retrospect. Segmentation anomalies and intraoperative judgment of stability were considered sufficient for identification of patients who require fusion in this subgroup. After induction of general anesthesia and muscle relaxation, one may encounter considerable hypermobilities not apparent on preoperative images. With the head securely fixed in the Mayfield clamp, the competence of $\mathrm{C} 1-2$ joints as well as those of the subaxial spine can be evaluated intraoperatively. Even though no objective criteria can be defined to diagnose instability during surgery, it is my experience that the intraoperative evaluation of C1-2 stability is a reasonable adjunct to decide whether a fusion is required.

Patients with basilar invagination without ventral compression, with no pre- or intraoperative evidence of instability but with abnormalities of segmentation in the upper cervical spine carry a considerable risk of postoperative instability if treated by a posterior decompression alone. Two of 7 such patients required a secondary stabilization later on in this series. Among such patients with segmentation anomalies treated at other institutions by posterior decompression without fusion, and who required a surgical revision, all had to undergo posterior fusion. Assessments of patients with secondary stabilizations revealed a considerably worse long-term outcome for occipital pain compared with all other patients. Several of them suffered from chronic pain syndromes requiring permanent analgesic medication.

The most likely explanation appears to be that the detachment of neck muscles from occiput and C-1 may cause problems in compensating their biomechanical handicaps sufficiently after surgery. Therefore, for patients in this subgroup-basilar invagination with no ventral compression but with segmentation anomalies-it is recommended

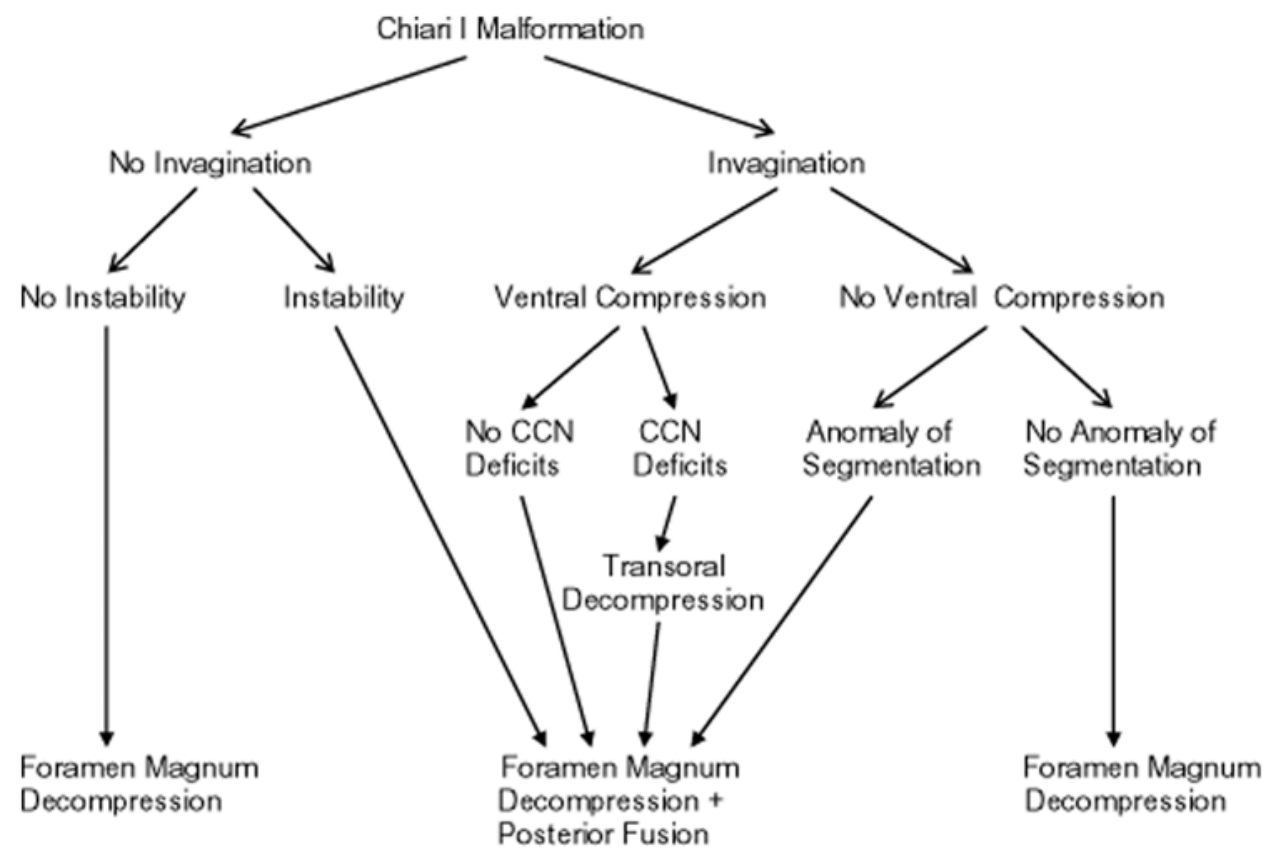

FIG. 9. Algorithm for surgical management of Chiari I malformation in patients with and without additional basilar invagination. $\mathrm{CCN}=$ caudal cranial nerves. 
that the foramen magnum decompression be combined with a stabilization procedure, even if no instability can be demonstrated before or during surgery. Patients with ventral compression should undergo a foramen magnum decompression with posterior realignment and fusion ${ }^{7}$ (Fig. 2). This realignment can be achieved by preoperative Crutchfield traction (Jürgen Harms, personal communication, 2001), ${ }^{24}$ a halo vest,${ }^{52}$ and distraction of $\mathrm{C} 1-2$ by intraarticular spacers ${ }^{17}$ or by intraoperative traction under neuromuscular blockade, ${ }^{11}$ as was done in this series. If $\mathrm{C} 1-2$ is mobile, such maneuvers will reduce ventral compressions to such a degree that anterior decompressions are no longer necessary. , $^{8,17,19,23,27,47}$ Fusion is then required to secure this corrected position permanently-irrespective of pre- or intraoperative evidence of instability.

If a posterior fusion is required, the occiput can be spared whenever the atlas is not assimilated to the occiput. ${ }^{22}$ Without abnormalities of the subaxial spine, an $\mathrm{Oc}-\mathrm{C} 2$ or $\mathrm{C} 1-2$ fixation can be sufficient. ${ }^{55}$ Experimental studies have confirmed the biomechanical safety of preserving realignment of the craniocervical junction by posterior distraction and fusion of $\mathrm{C} 1-2$ alone. ${ }^{12}$ With segmentation abnormalities or degenerative changes below C-2, the fixation can be extended caudally as required.

Can all patients with ventral compression be treated in this fashion? Are transoral decompressions obsolete? ${ }^{20}$ This is a controversial issue. Basilar invagination may reach a point that a sufficient reduction may no longer be possible by distraction. The younger the patient the more likely it is that extension will reduce an anterior compression. On the other hand, the combined decompressions in this series were particularly successful in improving caudal cranial nerve functions in particular. Similar observations were made by Salunke et al. for pediatric patients. ${ }^{50}$ Nobody can tell in retrospect whether the same results would have been obtained with posterior management alone. Looking at patients from recent years, the number of combined decompressions has gradually decreased in this series, because more cases than previously thought can indeed be managed well without transoral surgery. However, for adult patients with profound anterior compression and caudal cranial nerve deficits, a transoral decompression is still a sensible option (Fig. 3) and may still be required in patients in whom a realignment via the posterior approach was not successful.

Transoral decompressions should always be followed by a posterior fusion. Menezes et al. described a group of patients treated by ventral decompression alone without developing postoperative instability. ${ }^{39}$ In the literature, some reports describe stable situations after a transoral ${ }^{25}$ or transnasal resection ${ }^{15,51}$ of the odontoid in basilar invagination. However, the risks of postoperative instability are considerable. ${ }^{16,18,42,44}$ Early in this series, 1 patient without preoperative instability underwent a transoral decompression with no posterior fusion planned. This rendered him severely unstable while still in intensive care, and required posterior fusion immediately. Therefore, I cannot recommend stand-alone transoral decompressions. In a recent review, Menezes recommended posterior fusions after transoral resections of the odontoid in every patient as well. ${ }^{37}$

\section{Management of the Degenerative Cervical Pathology}

Another important aspect for patients with Chiari I malformations is the recognition of degenerative diseases of the cervical spine ${ }^{28,53}$ (Fig. 5). Most patients undergo a foramen magnum procedure at an age before they have developed significant degenerative problems in their cervical spines. However, due to the longstanding cord compression by cerebellar tonsils or the odontoid peg and the cord damage by an associated syrinx, the cervical cords of these patients are very vulnerable to degenerative spine diseases. Most patients will demonstrate some degree of cord atrophy despite a sufficient decompression and reduction of a syrinx. This may suggest that a cervical stenosis or a kyphotic angulation may be irrelevant. The significance of degenerative changes is easily overlooked unless functional studies of the cervical spine are performed. Hypermobilities appear to be particularly harmful to such an atrophic spinal cord. It is my experience that these patients should undergo cervical fusions as soon as clinical signs of a cervical myelopathy become apparent or progress. ${ }^{28}$ The results presented here suggest that posterior decompressions with laminectomies of C3-6 combined with lateral mass fixations may lead to better long-term results than ventral fusions, which tended to address the 1 or 2 most affected levels-only to be followed by adjacent-level disease soon thereafter.

\section{Complications After Foramen Magnum Decompressions}

The complication rate of $19.2 \%$ in this study is in the reported range for foramen magnum decompressions that incorporate a duraplasty. ${ }^{2,21,34,57}$ Lower rates are described for decompressions that leave the dura intact. ${ }^{36,45}$ In this study, complication rates were significantly higher for patients with invagination compared with those without (Table 4). Most of this difference was related to higher rates for postoperative pneumonia in the invagination group. The rates for local complications (i.e., CSF fistulas, hemorrhages, and so on), were almost identical. Only 3.2\% developed a postoperative ventricular dilation and clinical signs of increased intracranial pressure despite a sufficient decompression and required a ventriculoperitoneal shunt. This is a well-documented but not well-understood complication after foramen magnum decompressions for Chiari I malformations. This complication is not related to arachnoid opening or postoperative formation of subdural hygromas in the posterior fossa, ${ }^{29}$ but may in some way be related to the altered CSF flow at the foramen magnum, which some patients have problems adapting to in the immediate postoperative phase.

Swallowing dysfunctions and problems of opening the mouth are well-recognized complications after occipitocervical stabilizations, ${ }^{38}$ and may be aggravated further by short necks and smaller pharynx cavities in patients with invagination. In this series these dysfunctions were transient in 3 patients and did not require any measures apart from logopedic therapy. Such problems can be limited by meticulous positioning of the patient in neutral position. ${ }^{5,35,41,56}$ Care should be taken to avoid too much anteflexion, in particular. For that purpose, a preoperative lateral radiograph obtained in the neutral position is extremely helpful to aid correct positioning on the operating table under fluoroscopic control. 


\section{Outcome After Foramen Magnum Decompressions}

With the type of decompression performed in this study, $74 \%$ of patients with a syrinx experienced a sustained postoperative decrease in syrinx size, whereas $23 \%$ demonstrated no changes on postoperative MRI. For patients undergoing operation for the first time this figure was $83 \%$, and was considerably higher compared with studies in which the dura was left intact for treatment of a Chiari I malformation. ${ }^{9,45}$ Because syrinx cavities tended to be considerably smaller in patients with additional invagination, a higher percentage showed no postoperative change of syrinx size compared with patients who had Chiari I malformations without invagination.

Looking at clinical results in the 1st postoperative year, the overwhelming majority of patients experienced improvements for almost all symptoms,${ }^{23}$ as outlined in Table 5. Occipital pain responded best according to this analysis.

Contrary to other reports, ${ }^{1,4}$ basilar invagination was not associated with a worse long-term outcome compared with Chiari I malformation without invagination. This may be explained by the additional foramen magnum decompression as performed in this series. Long-term results were very gratifying for patients with invagination, as long as hardware failures could be avoided ${ }^{46}$ and no instability had resulted from the initial management. ${ }^{48}$ For patients without invagination, long-term results depended on the postoperative course of associated arachnoid pathologies. ${ }^{29}$ If the CSF pathway remained open, the rate for clinical recurrences was very low (Fig. 6). Revision surgeries, on the other hand, carried an increased risk for reobstructions leading to higher clinical recurrence rates due to the often severe arachnoid pathologies in this group ${ }^{28,29}$ (Fig. 7).

Compared with primary decompressions that leave the dura intact or incise only the outer layer, clinical recurrence rates greater than $10 \%$ are reported in the literature, with considerably smaller patient numbers and shorter follow-up. ${ }^{14,33,43,45,49}$ Pediatric neurosurgeons in particular favor this technique increasingly due to lower complication rates and shorter hospitalization times. However, none of these studies used Kaplan-Meier analyses to account for the varying follow-up times. If such analyses had been used, even higher clinical recurrence rates would have been the result. In this study, $6.5 \%$ of patients experienced a clinical recurrence after a first foramen magnum decompression, corresponding to a recurrence rate of $9.6 \%$ in 10 years according to Kaplan-Meier analysis. Therefore, a duraplasty should be part of each foramen magnum decompression. ${ }^{6,29}$ The results of this study demonstrate that the treatment algorithm presented here provides good shortand long-term results for patients with Chiari I malformations with or without an additional basilar invagination.

\section{Summary}

Symptomatic patients with a Chiari I malformation should undergo a foramen magnum decompression as outlined in this paper. In the absence of basilar invagination, craniocervical instability is a rare feature of this malformation, so that a posterior fusion is rarely required. If basilar invagination is combined with a Chiari I malformation, however, posterior fusion has to be performed along with the foramen magnum decompression whenever craniospinal instability is present or realignment of C1-2 has to be maintained to relieve a ventral compression of the medulla. This study also demonstrates that, in a significant number of patients with basilar invagination and no ventral compression by the odontoid, but with segmentation anomalies at $\mathrm{Oc}-\mathrm{C} 1$ or the subaxial spine, the craniocervical junction will become unstable after a foramen magnum decompression. Therefore, posterior fusion is recommended for these patients as well, irrespective of pre- or intraoperative signs of instability. The traditional method of treating an invagination by transoral odontoid resection followed by posterior fusion can be replaced by such a posterior operation in the great majority of patients. In this study, transoral decompressions were reserved for patients with ventral compression and significant dysfunctions of caudal cranial nerves. With the treatment algorithm as presented here, the great majority of patients reported sustained postoperative improvements, with no significant differences between those with or without additional basilar invagination.

\section{References}

1. Aghakhani N, Parker F, David P, Morar S, Lacroix C, Benoudiba F, et al: Long-term follow-up of Chiari-related syringomyelia in adults: analysis of 157 surgically treated cases. Neurosurgery 64:308-315, 2009

2. Aghakhani N, Parker F, Tadié M: [Syringomyelia and Chiari abnormality in the adult. Analysis of the results of a cooperative series of 285 cases.] Neurochirurgie 45 (Suppl 1):2336, 1999 (Fr)

3. Ali MM, Russell N, Awada A, McLean D: A cranio-cervical malformation presenting as acute respiratory failure. J

Emerg Med 14:569-572, 1996

4. Arora P, Behari S, Banerji D, Chhabra DK, Jain VK: Factors influencing the outcome in symptomatic Chiari I malformation. Neurol India 52:470-474, 2004

5. Bagley CA, Witham TF, Pindrik JA, Davis RF, Bydon A, Gokaslan ZL, et al: Assuring optimal physiologic craniocervical alignment and avoidance of swallowing-related complications after occipitocervical fusion by preoperative halo vest placement. J Spinal Disord Tech 22:170-176, 2009

6. Batzdorf U, McArthur DL, Bentson JR: Surgical treatment of Chiari malformation with and without syringomyelia: experience with 177 adult patients. J Neurosurg 118:232-242, 2013

7. Bollo RJ, Riva-Cambrin J, Brockmeyer MM, Brockmeyer DL: Complex Chiari malformations in children: an analysis of preoperative risk factors for occipitocervical fusion. $\mathbf{J}$ Neurosurg Pediatr 10:134-141, 2012

8. Botelho RV, Neto EB, Patriota GC, Daniel JW, Dumont PA, Rotta JM: Basilar invagination: craniocervical instability treated with cervical traction and occipitocervical fixation. Case report. J Neurosurg Spine 7:444-449, 2007

9. Caldarelli M, Novegno F, Vassimi L, Romani R, Tamburrini G, Di Rocco C: The role of limited posterior fossa craniectomy in the surgical treatment of Chiari malformation Type I: experience with a pediatric series. J Neurosurg 106 (3 Suppl):187-195, 2007

10. Chamberlain WE: Basilar impression (platybasia): a bizarre developmental anomaly of the occipital bone and upper cervical spine with striking and misleading neurologic manifestations. Yale J Biol Med 11:487-496, 1939 
11. Dahdaleh NS, Dlouhy BJ, Menezes AH: Application of neuromuscular blockade and intraoperative 3D imaging in the reduction of basilar invagination. J Neurosurg Pediatr 9:119-124, 2012

12. Daniel RT, Muzumdar A, Ingalhalikar A, Moldavsky M, Khalil S: Biomechanical stability of a posterior-alone fixation technique after craniovertebral junction realignment. World Neurosurg 77:357-361, 2012

13. Dickman CA, Kalani MY: Resolution of cervical syringomyelia after transoral odontoidectomy and occipitocervical fusion in a patient with basilar invagination and Type I Chiari malformation. J Clin Neurosci 19:1726-1728, 2012

14. Förander P, Sjåvik K, Solheim O, Riphagen I, Gulati S, Salvesen $\varnothing$, et al: The case for duraplasty in adults undergoing posterior fossa decompression for Chiari I malformation: a systematic review and meta-analysis of observational studies. Clin Neurol Neurosurg 125:58-64, 2014

15. Gladi M, Iacoangeli M, Specchia N, Re M, Dobran M, Alvaro L, et al: Endoscopic transnasal odontoid resection to decompress the bulbo-medullary junction: a reliable anterior minimally invasive technique without posterior fusion. Eur Spine J 21 (Suppl 1):S55-S60, 2012

16. Goel A: Progressive basilar invagination after transoral odontoidectomy: treatment by atlantoaxial facet distraction and craniovertebral realignment. Spine (Phila Pa 1976) 30:E551-E555, 2005

17. Goel A: Treatment of basilar invagination by atlantoaxial joint distraction and direct lateral mass fixation. J Neurosurg Spine 1:281-286, 2004

18. Goel A, Bhatjiwale M, Desai K: Basilar invagination: a study based on 190 surgically treated patients. J Neurosurg 88:962-968, 1998

19. Goel A, Shah A: Atlantoaxial joint distraction as a treatment for basilar invagination: a report of an experience with 11 cases. Neurol India 56:144-150, 2008

20. Goel A, Shah A: Reversal of longstanding musculoskeletal changes in basilar invagination after surgical decompression and stabilization. J Neurosurg Spine 10:220-227, 2009

21. Guo F, Wang M, Long J, Wang H, Sun H, Yang B, et al: Surgical management of Chiari malformation: analysis of 128 cases. Pediatr Neurosurg 43:375-381, 2007

22. Hwang SW, Heilman CB, Riesenburger RI, Kryzanski J: C1$\mathrm{C} 2$ arthrodesis after transoral odontoidectomy and suboccipital craniectomy for ventral brain stem compression in Chiari I patients. Eur Spine J 17:1211-1217, 2008

23. Jian FZ, Chen Z, Wrede KH, Samii M, Ling F: Direct posterior reduction and fixation for the treatment of basilar invagination with atlantoaxial dislocation. Neurosurgery 66:678-687, 2010

24. Joseph V, Rajshekhar V: Resolution of syringomyelia and basilar invagination after traction. Case illustration. J Neurosurg 98 (3 Suppl):298, 2003

25. Kaibara T, Hurlbert RJ, Sutherland GR: Intraoperative magnetic resonance imaging-augmented transoral resection of axial disease. Neurosurg Focus 10(2):E4, 2001

26. Kaplan EL, Meier P: Nonparametric estimation from incomplete observations. J Am Stat Assoc 53:457-481, 1958

27. Kim LJ, Rekate HL, Klopfenstein JD, Sonntag VKH: Treatment of basilar invagination associated with Chiari I malformations in the pediatric population: cervical reduction and posterior occipitocervical fusion. J Neurosurg 101 (2 Suppl):189-195, 2004

28. Klekamp J: Neurological deterioration after foramen magnum decompression for Chiari malformation type I: old or new pathology? J Neurosurg Pediatr 10:538-547, 2012

29. Klekamp J: Surgical treatment of Chiari I malformationanalysis of intraoperative findings, complications, and outcome for 371 foramen magnum decompressions. Neurosurgery 71:365-380, 2012
30. Klekamp J, Batzdorf U, Samii M, Bothe HW: The surgical treatment of Chiari I malformation. Acta Neurochir (Wien) 138:788-801, 1996

31. Klekamp J, Samii M: Introduction of a score system for the clinical evaluation of patients with spinal processes. Acta Neurochir (Wien) 123:221-223, 1993

32. Klekamp J, Samii M: Syringomyelia: Diagnosis and Treatment. Berlin: Springer, 2002

33. Krishna V, McLawhorn M, Kosnik-Infinger L, Patel S: High long-term symptomatic recurrence rates after Chiari-1 decompression without dural opening: a single center experience. Clin Neurol Neurosurg 118:53-58, 2014

34. Kumar R, Kalra SK, Vaid VK, Mahapatra AK: Chiari I malformation: surgical experience over a decade of management Br J Neurosurg 22:409-414, 2008

35. Matsunaga S, Onishi T, Sakou T: Significance of occipitoaxial angle in subaxial lesion after occipitocervical fusion. Spine (Phila Pa 1976) 26:161-165, 2001

36. McGirt MJ, Attenello FJ, Datoo G, Gathinji M, Atiba A, Weingart JD, et al: Intraoperative ultrasonography as a guide to patient selection for duraplasty after suboccipital decompression in children with Chiari malformation Type I. J Neurosurg Pediatr 2:52-57, 2008

37. Menezes AH: Craniovertebral junction abnormalities with hindbrain herniation and syringomyelia: regression of syringomyelia after removal of ventral craniovertebral junction compression. J Neurosurg 116:301-309, 2012

38. Menezes AH: Surgical approaches: postoperative care and complications "transoral-transpalatopharyngeal approach to the craniocervical junction." Childs Nerv Syst 24:11871193,2008

39. Menezes AH, VanGilder JC, Graf CJ, McDonnell DE: Craniocervical abnormalities. A comprehensive surgical approach. J Neurosurg 53:444-455, 1980

40. Milhorat TH, Chou MW, Trinidad EM, Kula RW, Mandell $\mathrm{M}$, Wolpert $\mathrm{C}$, et al: Chiari I malformation redefined: clinical and radiographic findings for 364 symptomatic patients. Neurosurgery 44:1005-1017, 1999

41. Miyata M, Neo M, Fujibayashi S, Ito H, Takemoto M, Nakamura T: O-C2 angle as a predictor of dyspnea and/or dysphagia after occipitocervical fusion. Spine (Phila Pa 1976) 34:184-188, 2009

42. Mouchaty H, Perrini P, Conti R, Di Lorenzo N: Craniovertebral junction lesions: our experience with the transoral surgical approach. Eur Spine J 18 (Suppl 1):13-19, 2009

43. Mutchnick IS, Janjua RM, Moeller K, Moriarty TM: Decompression of Chiari malformation with and without duraplasty: morbidity versus recurrence. J Neurosurg Pediatr 5:474478, 2010

44. Naderi S, Pamir MN: Further cranial settling of the upper cervical spine following odontoidectomy. Report of two cases. J Neurosurg 95 (2 Suppl):246-249, 2001

45. Navarro R, Olavarria G, Seshadri R, Gonzales-Portillo G, McLone DG, Tomita T: Surgical results of posterior fossa decompression for patients with Chiari I malformation. Childs Nerv Syst 20:349-356, 2004

46. Nockels RP, Shaffrey CI, Kanter AS, Azeem S, York JE: Occipitocervical fusion with rigid internal fixation: long-term follow-up data in 69 patients. J Neurosurg Spine 7:117-123, 2007

47. Peng X, Chen L, Wan Y, Zou X: Treatment of primary basilar invagination by cervical traction and posterior instrumented reduction together with occipitocervical fusion. Spine (Phila Pa 1976) 36:1528-1531, 2011

48. Plötz GM, Schütz U, Grob D: [Dorsal occipitocervical fusion-indications and results.] Z Orthop Ihre Grenzgeb 136:364-374, 1998 (Ger)

49. Sakushima K, Hida K, Yabe I, Tsuboi S, Uehara R, Sasaki $\mathrm{H}$ : Different surgical treatment techniques used by neurosur- 
geons and orthopedists for syringomyelia caused by Chiari I malformation in Japan. J Neurosurg Spine 18:588-592, 2013

50. Salunke P, Behari S, Kirankumar MV, Sharma MS, Jaiswal AK, Jain VK: Pediatric congenital atlantoaxial dislocation: differences between the irreducible and reducible varieties. J Neurosurg 104 (2 Suppl):115-122, 2006

51. Scholtes F, Signorelli F, McLaughlin N, Lavigne F, Bojanowski MW: Endoscopic endonasal resection of the odontoid process as a standalone decompressive procedure for basilar invagination in Chiari type I malformation. Minim Invasive Neurosurg 54:179-182, 2011

52. Simsek S, Yigitkanli K, Belen D, Bavbek M: Halo traction in basilar invagination: technical case report. Surg Neurol 66:311-314, 2006

53. Takeuchi K, Yokoyama T, Ito J, Wada K, Itabashi T, Toh S: Tonsillar herniation and the cervical spine: a morphometric study of 172 patients. J Orthop Sci 12:55-60, 2007

54. Ursekar M, Sanghvi D, Shah A, Goel A, Burute N: Radiological investigations, in Goel A, Cacciola F (eds): The
Craniovertebral Junction. Diagnosis, Pathology, Surgical Techniques. Stuttgart: Thieme, 2011, p 54-70

55. Yin YH, Yu XG, Qiao GY, Guo SL, Zhang JN: C1 lateral mass screw placement in occipitalization with atlantoaxial dislocation and basilar invagination: a report of 146 cases. Spine (Phila Pa 1976) 39:2013-2018, 2014

56. Yoshida M, Neo M, Fujibayashi S, Nakamura T: Upper-airway obstruction after short posterior occipitocervical fusion in a flexed position. Spine (Phila Pa 1976) 32:E267-E270, 2007

57. Zhang ZQ, Chen YQ, Chen YA, Wu X, Wang YB, Li XG: Chiari I malformation associated with syringomyelia: a retrospective study of 316 surgically treated patients. Spinal Cord 46:358-363, 2008

\section{Correspondence}

Jörg Klekamp, Department of Neurosurgery, Christliches Krankenhaus, Danziger Str. 2, 49610 Quakenbrück, Germany. email: j.klekamp@ckq-gmbh.de. 